\title{
Peripartum cardiomyopathy: a rare complication in a teenage pregnancy
}

\author{
Uma Chourasia ${ }^{1 *}$, Jyoti Nath Modi $^{2}$
}

\author{
${ }^{1}$ Department of Obstetrics and Gynecology, College of Medicine, Jazan University, Jazan, Saudi Arabia \\ ${ }^{2}$ Department of Obstetrics and Gynecology, AIIMS, Bhopal, Madhya Pradesh, India
}

Received: 07 May 2021

Accepted: 28 May 2021

\section{*Correspondence:}

Dr. Uma Chourasia,

E-mail: drumahchourasia@gmail.com

Copyright: (C) the author(s), publisher and licensee Medip Academy. This is an open-access article distributed under the terms of the Creative Commons Attribution Non-Commercial License, which permits unrestricted non-commercial use, distribution, and reproduction in any medium, provided the original work is properly cited.

\begin{abstract}
The aim of this case report was to present a rare case of peripartum cardiomyopathy (PPCM) in an adolescent primigravida, and discuss its presentation and successful management. PPCM is a relatively rare yet life threatening cardiac complication of pregnancy. It often remains undiagnosed as its symptoms may simulate the physiological symptoms of pregnancy and peripartum period. An early diagnosis is crucial for improving survival. We herein report an unusual case of PPCM in an young and otherwise healthy primigravida. A 19-year-old primigravida presented at 33 weeks of gestation with, severe pre-eclampsia with dyspnea, cough and discomfort in the chest. Based on clinical findings and ECG, the echocardiography was done, and a definitive diagnosis of PPCM was made. The patient was managed for heart failure and preeclampsia by a multidisciplinary team. Emergency cesarean was done for obstetric indication and patient was managed conservatively in intensive care unit. Patient improved clinically and was discharged at day 10. Peripartum cardiomyopathy though typically associates with advanced maternal age can occur in very young women as well. A high index of suspicion for PPCM is recommended on a background of `severe preeclampsia with breathlessness. Timely echocardiography for diagnosis, and a multidisciplinary team approach are a key to successful management. Clinical significance of the study was to shed new light on the unusual presentation of PPCM and to contribute to the existing knowledge of PPCM.
\end{abstract}

Keywords: Echocardiography, Heart failure, Peripartum cardiomyopathy, Severe pre-eclampsia, Teenage pregnancy

\section{INTRODUCTION}

Peripartum cardiomyopathy (PPCM) is defined as an idiopathic dilated cardiomyopathy in absence of any preexistent heart disease during late pregnancy or in the first 5 months postpartum. ${ }^{1}$ It is diagnosed after excluding other identifiable causes of heart failure. Left ventricular systolic dysfunction, reduced $(<45 \%)$ ejection fraction and an end-diastolic dimension index of greater than $2.7 \mathrm{~cm} / \mathrm{m}^{2}$ demonstrated by echocardiography constitute the diagnostic criteria. ${ }^{2,3}$ The PPCM though rare is a lifethreatening condition with a high mortality ranging from $7 \%$ to $50 \% .^{4}$ Its incidence, ranges from 1:100 to $1: 20,000$, varying with the race and geographical region. The countries such as Nigeria, South Africa, and Haiti report a high incidence, while it is low in places like Scandinavia and Japan. The African population has three to four-fold increased incidence compared to the Hispanics who have the lowest reported incidence. ${ }^{5-7}$ The exact etiology of the disease remains unclear.

The current hypotheses suggest the role of genetic predisposition, autoimmune mechanism and vascular dysfunction caused by cardio toxic prolactin sub fragment and placental anti-angiogenic protein in the pathophysiology of PPCM. ${ }^{7}$ The various risk factors are African ethnicity, advanced maternal age (>30 years), multiparity, multiple gestation, pre-eclampsia, gestational hypertension, obesity, anemia and prolonged tocolysis. However, the disease may occur in the absence of any of 
these risk factors as well. A rare case of PPCM in a teenage primigravida that was successfully managed by a multidisciplinary team is presented here.

\section{CASE REPORT}

A 19-years-old primigravida presented at 33 weeks of pregnancy to the emergency labor room with dyspnea, cough and chest discomfort for the last 2 days at Peoples Hospital, Bhopal, the affiliated hospital of Peoples College of Medical Sciences and Research Centre (PCMS \& RC), Bhopal, (both authors were formerly working as faculty in the department of OBGY at PCMS\& RC). Her medical history was otherwise unremarkable. She denied any history of pre-existing heart disease, autoimmune disease, allergy or prolonged use of tocolytic medication. Her antenatal period had been uneventful until then, and she was taking her prenatal vitamins regularly. On physical examination, she was afebrile, had tachycardia with a pulse rate of 108 beats per minute, blood pressure of $180 / 120 \mathrm{mmHg}$, and a respiratory rate of 46 breaths per minute. She had mild pallor, bilateral pitting pedal edema with no calf tenderness and bibasilar coarse crepitations. Her oxygen saturation was $68 \%$ (on room air) that improved to $80 \%$ with nasal oxygen supplementation. Urine protein was ' ++ ' on urine dipstick examination. Other laboratory investigations were within normal limits. On Obstetric examination the uterus corresponded to 32 weeks size with a single alive fetus in cephalic presentation with a fetal heart rate 110 beats per minute. On vaginal examination, the cervix was un-effaced and the os was closed. On ultrasonography, there was a single live fetus with fetal biometry corresponding to 31 weeks gestation.
The cardiotocograph (CTG) on admission showed a nonreassuring fetal heart rate pattern.

The ECG showed sinus tachycardia, $\mathrm{T}$ wave inversion and $\mathrm{R}$ wave poor progression in V2 to V6 (Figure1). Chest radiograph revealed cardiomegaly with bilateral pulmonary infiltrates. Echocardiography showed severe LV dysfunction, EF $35 \%$, FS $<20 \%$. This confirmed the diagnosis of PPCM after excluding other possible causes of heart failure. The team of physicians, anesthetists and obstetricians started standard heart failure and preeclampsia management.

An emergency caesarean section was done under general anesthesia for severe preeclampsia and fetal distress, and a preterm female baby with birth weight of $1.6 \mathrm{~kg}$ was delivered. The baby was kept in neonatal intensive care unit in view of prematurity. Postoperatively, the patient was shifted to intensive care unit and was put on ventilator. Patient was extubated after 12 hours. Significant clinical improvement occurred after 2 days of treatment with diuretics, angiotensin converting enzyme inhibitors, digoxin and vasodilators. After 10 days of therapy the echocardiography study was normal (Figure 2) and the patient was discharged.

The patient and her family were counselled about the prognosis of the disease and options of contraception were discussed. At follow up after 2 weeks patient was asymptomatic.

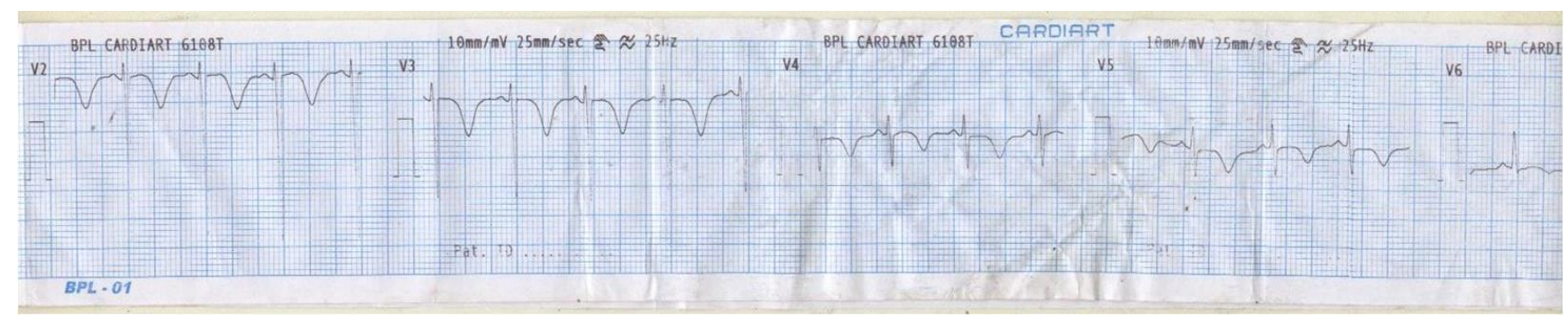

Figure 1: Showing sinus tachycardia, $T$ wave inversion and poor progression of $R$ wave in V2-V6.

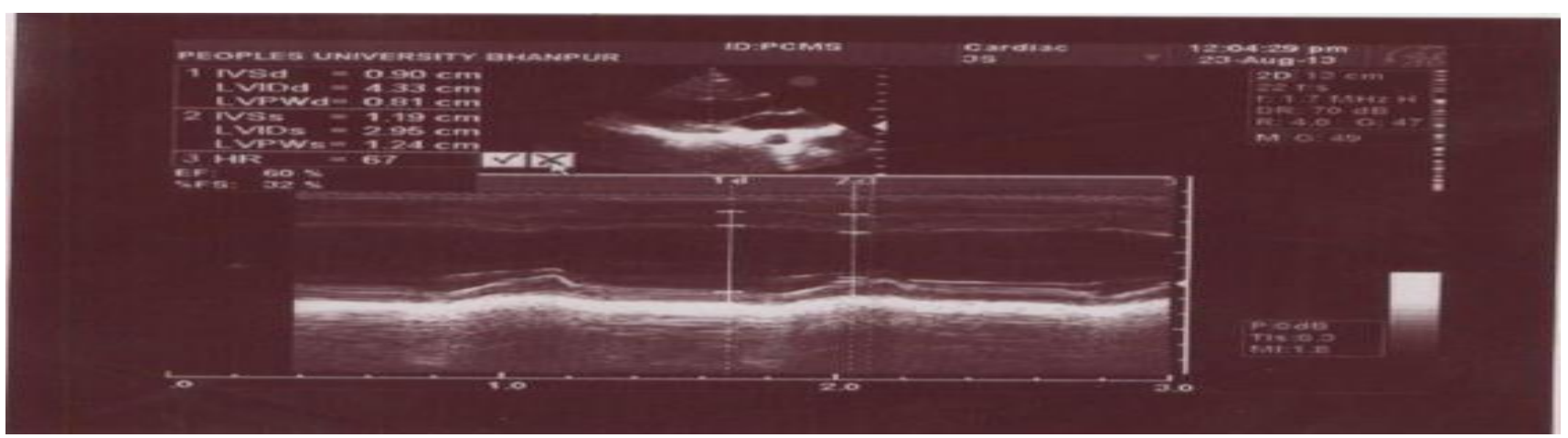

Figure 2: Normal echocardiography with EF-60\%, FS-32\% on post-operative day 10. 


\section{DISCUSSION}

PPCM is a relatively rare complication associated with advanced maternal age (>30 years), African ethnicity, multiparity, multiple pregnancy, pre-eclampsia, smoking, diabetes. However nowadays the incidence is rising in young primigravida and white women. ${ }^{8,9}$ The reported mortality is high in teenage pregnant women. ${ }^{10}$ PPCM often remains undetected or misdiagnosed as the heart failure symptoms of PPCM mimic the physiological symptoms of late pregnancy and early puerperium. Echocardiography is the current gold standard for confirmation of the diagnosis. A high index of suspicion, proper evaluation of clinical symptoms and adherence to the strict echocardiographic criteria are essential for early and definite diagnosis of PPCM. ${ }^{11}$

In the present case, the high-risk factors identified were the presence of severe preeclampsia, and young age. The out of proportion cardiac symptoms rose the suspicion and the diagnosis could be made timely. It is our learning from this case and as also recommended in guidelines, the presence of symptoms of heart failure and a delay in normalizing of pregnancy related symptoms in the post delivery period merits further evaluation by the physician and an echocardiography. An early involvement of multidisciplinary team in our case helped us to manage it successfully.

Early diagnosis and proper treatment of PPCM reduce the life threatening complications and increase survival with a better recovery of cardiac function. ${ }^{12}$ Patients with LVEF $>30 \%-35 \%$ and small LV diastolic dimension $(<5.5-6.0$ $\mathrm{cm})$ at presentation show favorable prognosis. ${ }^{13}$ Within 6 months, $50-80 \%$ of patients recover the normal cardiac function (LVEF $\geq 50 \%$ ). ${ }^{7}$ Patients with LVEF $<30 \%$ at the time of diagnosis, experience worse prognosis with more chances of relapse. Persistence of disease after 6 months indicates poor prognosis.

Echocardiography is also extremely valuable in formulating prognosis and following the course of the disease. PPCM recurrence in subsequent pregnancies may be as high as $46 \%$, particularly among women with LVEF $<55 \%$ before pregnancy. ${ }^{14,15}$ Even after complete restoration of cardiac function the risk of recurrence remains high. ${ }^{1}$ Persistence of left ventricular dysfunction is a relative contra-indication to plan a future pregnancy and subsequent pregnancies should be discouraged in such patients. ${ }^{16-18}$ Our aim at reporting this case of PPCM was to heighten the awareness about this rare, silent and yet life threatening condition and to emphasize its early and definite diagnosis with echocardiography. The role of multidisciplinary patient care teams cannot be over emphasized in such situations.

\section{CONCLUSION}

The obstetricians must keep a high index of suspicion for peripartum cardiomyopathy in women with unexplained or out of proportion pulmonary edema during pregnancy or early puerperium. Timely diagnosis and multidisciplinary team approach are crucial in the management of PPCM for reducing mortality and increasing the chances of complete recovery of ventricular systolic function.

\section{Clinical significance of case}

Clinical significance of the case was (a) PPCM is a rare complication of pregnancy and its occurrence in an otherwise healthy teenage primigravida is rarer; (b) to contribute to the available literature for future epidemiologic studies of possible etiology, symptomatology and complications; and (c) experience sharing is an important aspect of learning mainly in such rare and fatal disease.

\section{ACKNOWLEDGMENTS}

Authors express their sincere gratitude to Dr. Anil Kapoor from internal medicine and Dr. Ashwin Chaudhary from anesthesia and critical care, for their valuable contribution in the management of the patient.

Funding: No funding sources

Conflict of interest: None declared

Ethical approval: Not required

\section{REFERENCES}

1. Sliwa K, Hilfiker KD, Petrie MC, Mebazaa A, Pieske B, Buchmann E, et al. Current state of knowledge on aetiology, diagnosis, management, and therapy of peripartum cardiomyopathy: a position statement from the Heart Failure Association of the European Society of Cardiology Working Group on peripartum cardiomyopathy. Eur J Heart Fail. 2010;12(8):767-78.

2. Hibbard JU, Lindheimer M, Lang RM. A modified definition for peripartum cardiomyopathy and prognosis based on echocardiography. Obstet Gynecol. 1999;94(2):311-6.

3. Pearson GD, Veille JC, Rahimtoola S, Hsia J, Oakley CM, Hosenpud JD, et al. Peripartum cardiomyopathy: National Heart, Lung, and Blood Institute and Office of Rare Diseases (National Institutes of Health) workshop recommendations and review. JAMA. 2000;283(9):1183-8.

4. Okeke T, Ezenyeaku C, Ikeako L. Peripartum cardiomyopathy. Ann Med Health Sci Res. 2013;3(3):313-9

5. Brar SS, Khan SS, Sandhu GK, Jorgensen MB, Parikh N, Hsu JW, Shen AY. Incidence, mortality, and racial differences in peripartum cardiomyopathy. Am J Cardiol. 2007;100(2):302-4.

6. Isogai T, Kamiya CA. Worldwide Incidence of Peripartum Cardiomyopathy and Overall Maternal Mortality. Int Heart J. 2019;60(3):503-11.

7. Honigberg MC, Givertz MM. Peripartum cardiomyopathy. BMJ. 2019;364:5287. 
8. Wang M. Peripartum cardiomyopathy: case reports. Perm J. 2009;13(4):42-5.

9. Elkayam U, Akhter MW, Singh H, Khan S, Bitar F, Hameed A, et al. Pregnancy-associated cardiomyopathy: clinical characteristics and a comparison between early and late presentation. Circulation. 2005;111(16):2050-5.

10. Zagrosek V, Roos HJW, Bauersachs J, Blomstrom LC, Cifkova R, De BM, et al. ESC Guidelines for the management of cardiovascular diseases during pregnancy. Eur Heart J. 2018;39(34):3165-241.

11. Albakri A. Peripartum cardiomyopathy: a review of literature on clinical status and meta-analysis of diagnosis and clinical management. J Integr Cardiol. 2018;4(3).

12. Fett JD. Earlier detection can help avoid many serious complications of peripartum cardiomyopathy. Future Cardiol. 2013;9(6):809-16.

13. Chapa JB, Heiberger HB, Weinert L, Decara J, Lang RM, Hibbard JU. Prognostic value of echocardiography in peripartum cardiomyopathy. Obstet Gynecol. 2005;105(6):1303-8.

14. Fett JD, Fristoe KL, Welsh SN. Risk of heart failure relapse in subsequent pregnancy among peripartum cardiomyopathy mothers. Int $\mathbf{J}$ Gynaecol Obstet. 2010;109(1):34-6.
15. Elkayam U, Tummala PP, Rao K, Akhter MW, Karaalp IS, Wani OR, et al. Maternal and Fetal Outcomes of Subsequent Pregnancies in Women with Peripartum Cardiomyopathy. New England J Med. 2001;344(21):1567-71.

16. Mandal D, Mandal S, Mukherjee D, Biswas SC, Maiti TK, Chattopadhaya N, et al. Pregnancy and subsequent pregnancy outcomes in peripartum cardiomyopathy. J Obstet Gynaecol Res. 2011;37(3):222-7.

17. Irizarry OC, Levine LD, Lewey J, Boyer T, Riis V, Elovitz MA, et al. Comparison of Clinical Characteristics and Outcomes of Peripartum Cardiomyopathy Between African American and Non-African American Women. JAMA Cardiol. 2017;2(11):1256-60.

18. Namara DM, Elkayam U, Alharethi R, Damp J, Hsich E, Ewald G, et al. Clinical Outcomes for Peripartum Cardiomyopathy in North America: Results of the IPAC Study (Investigations of Pregnancy-Associated Cardiomyopathy). J Am Coll Cardiol. 2015;66(8):905-14.

Cite this article as: Chourasia U, Modi JN.

Peripartum cardiomyopathy: a rare complication in a teenage pregnancy. Int J Reprod Contracept Obstet Gynecol 2021;10:2854-7. 